\title{
Reconstructing the Music Hall Rotunda and Annex at Vauxhall Pleasure Gardens c. 1764
}

\author{
Stephen Caffey \\ Department of Architecture \\ Texas A\&M University \\ 3137 TAMU \\ College Station TX 77843 \\ USA \\ stephencaffey@tamu.edu \\ Wei Yan \\ Department of Architecture \\ Texas A\&M University \\ 3137 TAMU \\ College Station TX 77843 \\ USA \\ wyan@tamu.edu
}

\author{
Robert G. Graf \\ Department of Visualisation \\ Texas A\&M University \\ 3137 TAMU \\ College Station TX 77843 \\ USA \\ goof@tamu.edu \\ Ehsan Barekati \\ Department of Architecture \\ Texas A\&M University \\ 3137 TAMU \\ College Station TX 77843 \\ USA \\ ehsan.barekati@tamu.edu
}

\author{
Charles Culp \\ Department of Architecture \\ Texas A\&M University \\ 3137 TAMU \\ College Station TX 77843 \\ USA \\ cculp@tamu.edu
}

\author{
Matthew Marshall \\ Department of Architecture \\ Texas A\&M University \\ 3137 TAMU \\ College Station TX 77843 \\ USA \\ mcm06@tamu.edu
}

\begin{abstract}
This paper summarises work in progress on the digital reconstruction of the structure, space and decorative program of the music hall and annex at Vauxhall Pleasure Gardens c. 1764.The proposed outcome will be a recreation of the space and its contents combining Building Information Modelling in programs such as Revit with panoramic interior views of the larger-thanlife modern-subject history paintings of scenes from and allegories based upon England's victories in the Seven Years' War, marble busts of British worthies and mirrors. The final version of the project will also include a choral and instrumental musical element, as the space was physically connected to the garden's indoor orchestral performance space.
\end{abstract}

Reconstructive architecture. Historic sites. Visualisation. Gallery display. Music.Animation.

\section{INTRODUCTION}

Vauxhall Pleasure Gardens, a twenty-acre enclosure located across the Thames and south from Westminster, served as one of London's most popular leisure destinations from 1661 to 1859 (see Figure 1).No material remains appear at the original location today; however, surviving textual and visual representations reveal the site's complexities (see Figure 2). 'Vauxhall'sgrounds included open and covered walkways, exotic and fanciful architecture, statuary, paintings, illuminated transparencies, musical performances, fireworks displays, supper boxes and a mechanical 'waterfall'. Among the garden's most striking features was the Music Hall, a rotunda connectedto a small orchestra box on one side and to an arched 'saloon'annex on the other.Upon entering the annex from the garden, one passed through an ornate gothic-style portal before encountering four large-scale modern-subject history paintings, the likes of which had not appeared in England prior to their installation in the saloon between 1760 and
1764.Beyond the annex was the rotunda space, 70 feet in diameter, with large windows, marble busts and oval mirrors flanked by sconces. In the centre of the space hung a chandelier of 11 feet in diameter with 72 large flickering candles. The light from these candles and from the sconces reflected off the mirrors, activating the surfaces of the canvases in the saloon, effectively bringing the figures to life. While moving into and through the rotunda space, one might hear any number of musical numbers performed by vocalists who were accompanied by the orchestra, the members of which sat in a small space opposite the gothic portal. Among the compositions most frequently performed at Vauxhall, the rousing 'Rule, Britannia!' was certainly one of the most popular - especially following England's global imperial gains in the Seven Years' War. Following the closing of the gardens in July of 1859, the contents of the garden were sold at auction. The four large history paintings survive only in the forms of modelli, engravings and textual descriptions. These paintings, as experienced in the stimulating 
environs of the Music Hall rotunda and annex, played a central role in the forging of visual literacy in the Anglophone cultures of the 18th century. This project seeks to recreate the spatial effect of the Music Hall rotunda and annex through an Interactive Building Information Modelling [IBIM] game platform designed to simulate the visual and aural details that engaged visitors' senses.

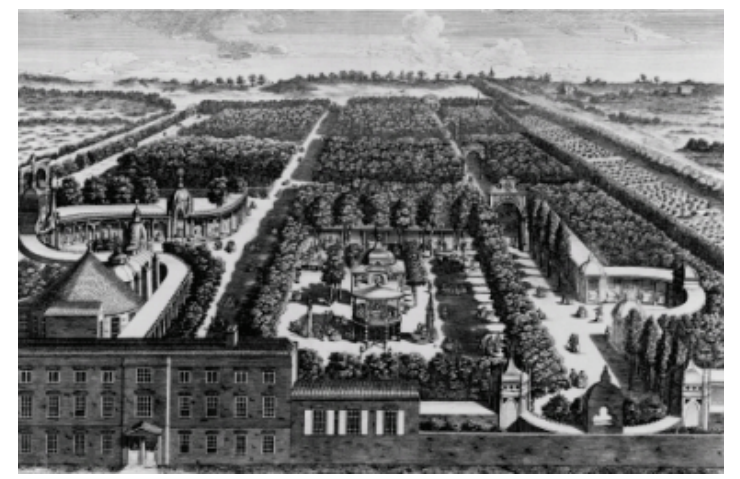

Figure 1: J.S. Muller after Samuel Wale, View ofVauxhall Pleasure Gardens

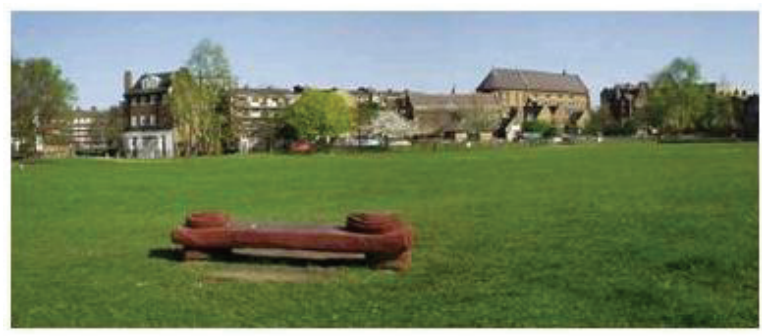

Figure 2: Vauxhall Gardens site as it appears today

\section{RATIONALE}

Recent trends in digital humanities research, theory and praxis suggest that virtual reconstructions of designed and built environments go beyond reconstructive illustration to aid in the recovery of objective archaeological data. In its current state, the Vauxhall IBIM project extends the role of twodimensional and three-dimensional digital technologies beyond data recovery to simulateand recover subjectiveaffective experience within such designed and built environments. iii As Sarah Kenderdine notes, panoramic structural and spatial environments express the 'desire to design virtual spaces and places that can be inhabited by the viewer - to maximise a sense of immersion and ultimately "presence" in...past environments'. iv By introducing the viewer/visitor into a panoramic virtual space in which s/he encounters ambient stimuli that augment the aesthetic experience of representational form, the Vauxhall IBIM project transformspassive 'period eye' reception into a more active reception structured as 'period Sensorium'. 'Viewers familiar with today's UNESCO
World Heritage Organisation panophotographies interactive immersion initiative will find that Vauxhall IBIM 'collapses time' in much the same way that the UNESCO site 'collapses space'. 'In its final state, our project will allow visitors to exploresome of the conditions in which visual and spatial literacies formed in 18th-century Anglophone societies.

\section{OBJECTIVES}

Vauxhall IBIM will serve as both research archive and instructional tool for scholars and students who study the visual cultures of $17^{\text {th }}$ through $19^{\text {th }}$ century Anglophone societies.Toward that goal, we define the following objectives:

- Employ architectural design software and gaming programs individually and in combination to advance digital humanities technologies.

- Innovate a foundation from which the entirety of Vauxhall Pleasure Gardens can be virtually reconstructed.

- Generate an immersive, interactive environment in which the visitor/participant can choose between first-person and thirdperson views and alternate between various versions of structures, spaces, decorative elements and viewing conditions.

- Afford scholars of art, architectural and cultural history to propose alternative reconstructions of Vauxhall structures, spaces and experiences.

- Function as an open source template for other scholarswho wish to recover forms, contents, effects and affects from historical sites and eras for which little or no documentary evidence survives and for which affective experience is of equal as or more important than accuracy of rendering and reconstruction.

\section{MODEL}

The design team has faced a number of challenges in conceptualising the basic architectural framework for the project. As no architects participated in the design and construction of Vauxhall features, no single authoritative archival sourcesupports conclusive historical authentication of a Music Hall rotunda and annex reconstruction. Distortions and inconsistencies within and between available sources necessitated compromises in order toproduce analoguecomposite drawings so that the project could move forward. Because 18thcentury images of Vauxhall were not produced for the purpose of providing architectural information, a 
number of proposals emerged from the initial analyses. Proposed designs that were not selected during the initial stages of the project will be retained for future use in adding gaming functionality that allows the viewer to propose alternative combinations structural, spatial and decorative forms.

The initial plans, sections and elevations of the structure were estimated from the most consistently reported rotunda diameter, from visual representations of the exterior of the structure and from various site plans (see Figures 3-5). The analogueplan, section and elevation will be transcribed into Autodesk ${ }^{\circledR}$ Revit ${ }^{\circledR}$ Building Information Modelling software to produce the forms, surfaces and spaces in and upon which various combinations of detailing and light effects may be introduced. As the project advances, decorative elements will be selected from textual descriptions and visual representations with an emphasis on chronological specificity to reflect renovation and expansion prior to and after 1764.Along with these details, light effects will be added via texture mapping with Autodesk $^{\circledR}$ 3DS Max ${ }^{\circledR}$ modelling, animation and rendering software. Once the base model detailing is complete, the sound file will be attached so that the music feature is activated upon the visitor's entry into the saloon.

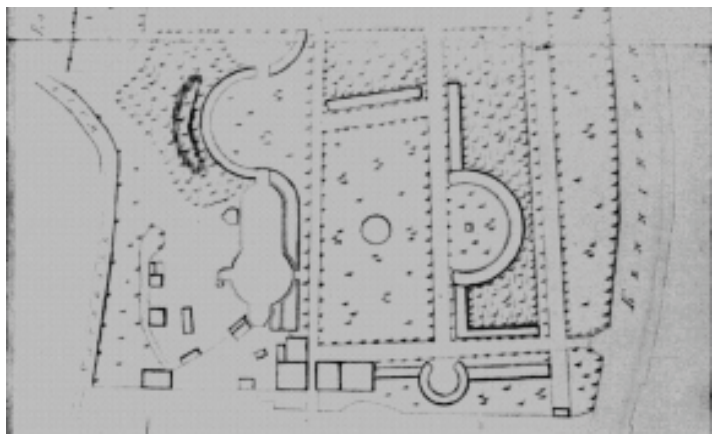

Figure 3: Detail, Vauxhall site plan

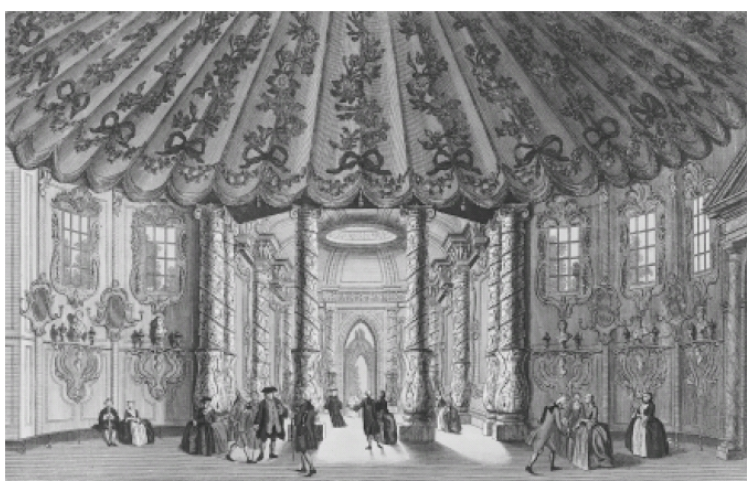

Figure 4: H. Roberts after Samuel Wale. The Inside of the Elegant Music Room in Vauxhall Gardens (after 1751)

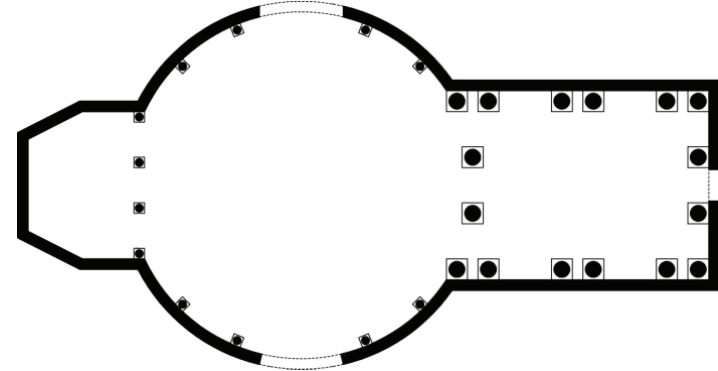

Figure 5: Interpretive plan of Music Hall rotunda and annex at Vauxhall Pleasure Gardens (Matthew Marshall)

\section{STRUCTURE}

The virtual tour begins as the viewer steps from beneath the gothic portal into the saloon annex. Flanking the portal are two large 'three-quarter' columns set on square bases which give rise to slightly bulbous forms festooned with vegetal forms. Atop these sections appear cylinders adorned with diagonally-spiralling decorative elements. The columns terminate in composite capitals. As the viewer directs her gaze to the left and right, she finds two large-scale modern-subject history paintings that face one another across the interior space of the saloon. Beyond each of these paintings rises a set of columns identical to those that flank the entrance. The viewer next encounters another duo of modern-subject history paintings hung opposite one another and of the same dimensions as the first set. In the IBIM model, two of these paintings will be based upon preparatory works by the original artist, with one fashioned after an engraving based on a painting and one derived from a painting by Irish artist James Barry that we believe to be at least partially based on the fourth work installed in the annex.

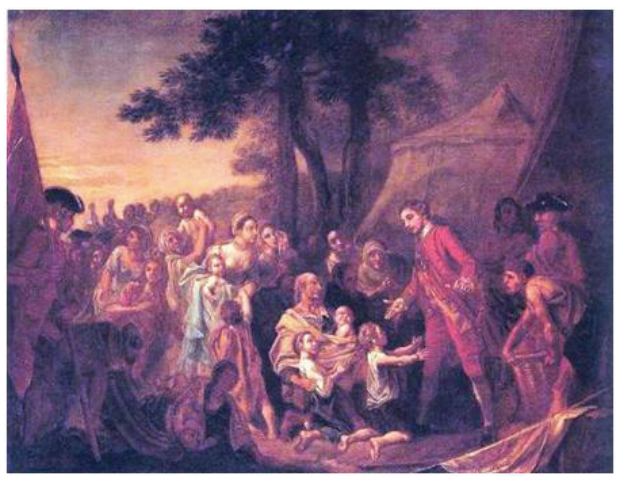

Figure 6: Francis Hayman, Modello for The Surrender of Montreal to General Amherst(c. 1760) 


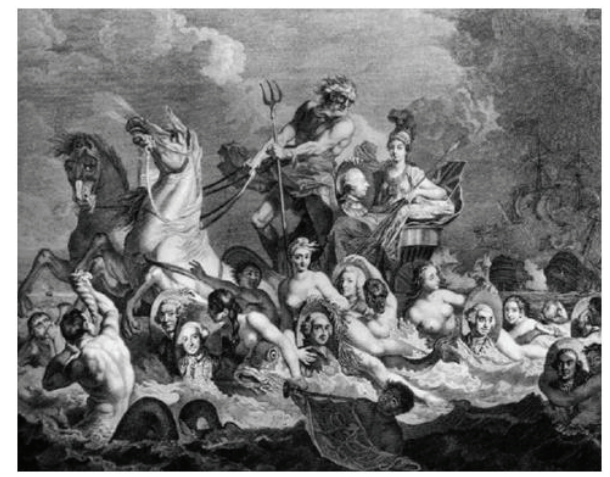

Figure 7: Simon Ravenet after Francis Hayman, The Triumph of Britannia (1765)

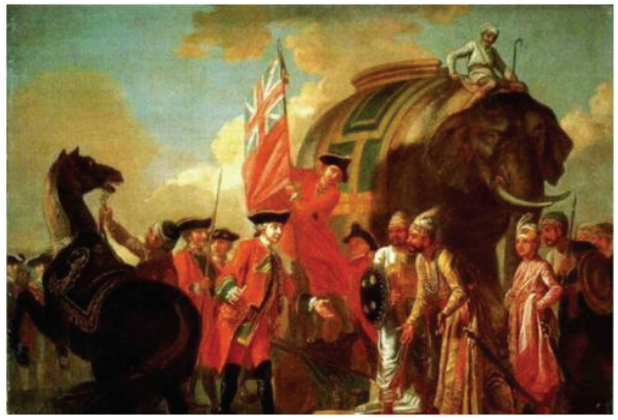

Figure 8: Francis Hayman, Modello for Lord Clive Receiving the Homage of the Nabob (c. 1761)

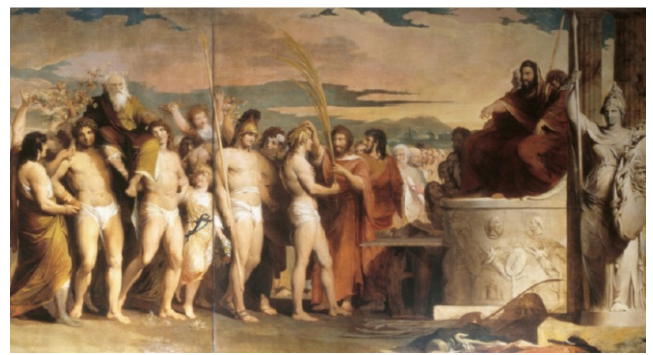

Figure 9: James Barry, Britannia Crowning the Victors at Olympia (1777)

The saloon walls terminate in a second pair of three-quarter columns and the space is demarcated by two free-standing columns of the same design as the others, bringing the total number of the columns of this design to 12 .

Once the viewer has passed between these freestanding columns into the cylindrical rotunda space, her attention is drawn upward by the domed ceiling, the appearance of which resembles that of the interior of an umbrella. Painted ribbons and flowers adorn the centre of each segment of the dome, which terminates in a curve that gives the appearance of scalloping. A painted tassel appears at the junction of the scallops. As the viewer's eye moves downward in the space, she encounters 16large sash windows, each with a decorative plume associated with Frederick, Prince of Wales who died unexpectedly in 1751. ${ }^{\text {vii }}$ Set between and beneath each pair of windows is an ornately framed oval mirror. One of 16 marble portrait busts of celebrated Britons attaches to brackets beneath each window. A classical-style vase rests on a shelf on either side of each marble bust. Each shelf surmounts a Rococo relief carved in plaster of Paris. A bench for seating runs continuously around the base of the rotunda walls, interrupted only by a niche/doorway temple form with thin columns topped by a pediment that appears to the viewer's left as she crosses from the saloon into the rotunda space. Opposite the gothic portal entrance to the saloon the rotunda opens into a small orchestra space which housed musicians during inclement weather.

Though a digital reconstruction of the structure, space and decorative features of Vauxhall's Music Hall rotunda and annex would prove a sufficiently valuable tool for scholarly investigation, the focus of this project is the recreation of the sensory stimuli that triggered affective experience. The elements that most strongly influenced the emotional and sensory registration of the experience include lighting, mirrors and music. Prior to sunset the interior of the annex would be illuminated by two ten-panel skylights set into cupolas atop the double-domed spaced of the saloon. As night fell, workmen would light the candles of the two chandeliers made to resemble baskets of flowers descending from the centre of each cupola. The light from these candles would flicker as small gusts of summer breeze entered through the portal. The flickering would activate the surfaces of the four large paintings, creating the illusions of life and movement in the figures depicted there in. This effect would be dramatically heightened by the light from the rotunda chandelier, which measured 11 feet in diameter and contained 72 candles encased in glass 'balls' arranged on three tiers. This chandelier would light the rotunda once the sunlight pouring in from the 16 large sash windows had faded into dusk.

Adding yet another degree of sensory intensity to the experience would be the 16 oval mirrors, which would increase the luminosity of the space while also reflecting the viewer's image at the same level of the annex paintings. The paintings introduced persons living and recently dead into the academic genre of history painting, an artistic realm formally reserved for characters from classical and scriptural narrative. The mirrors would metaphorically elevate the viewer to that exalted realm by creating 16 identical portraits that 'hung'

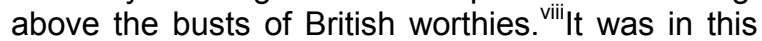
space while looking at these paintings under these conditions that Britons began to forge their newly imperial identity following the Seven Years' War. 
This fact is perhaps best articulated in the inscription painted onto a 'commemorating stone' in Hayman's The Surrender of Montreal to General Amherst:'POWER EXERTED, CONQUEST OBTAINED, MERCY SHEWN!'ix

Music Hall crowds were at their largest when weather conditions prevented the performance of music in the outdoor orchestra pavilion that stood to the viewers' left as they entered the gothic portal of the annex. Dozens of familiar popular songs were performed each season. New compositions were also debuted at Vauxhall and some tunes were commissioned specifically for performance in the gardens. Among the songs performed in the Music Hall, the David Mallet-Thomas Arne collaboration entitled 'Rule, Britannia!' would have resonated strongly with audiences in 1764.Other songs performed at Vauxhall included lyricsrelevant to recent British military history (and thus appropriate for the Music Hall annex exhibition space):'While our fam'd British bands, / Noble Granby commands, / ...Vict'ry drops from the sky, / And she crowns his bald head like a Cæsar' and 'What brave Wolfe has begun, gallant Amherst has done. / And subdu'd the whole Empire in Glory, / While the Kings of the East, are by Brave Clive supprest, / Like a hero and rival in Story. ${ }^{\text {,T }}$ The emotional impact of the paintings so lit, with the rousing soundtrack of imperial glory amplifying the sensory intensity would have inspired Vauxhall audiences. The potent associations between the sensory experience of the paintings and their form and content had an enormous impact on the course of British history painting in the 18th century. From the visual literacies cultivated in the Music Hall annex developed an unprecedented taste for history painting that in turn led to the foundation of the Royal Academy in 1768.

\section{PROTOTYPE}

We have created a prototype of Interactive Building Information Modelling that can visualise the Music Hall rotunda and annex at Vauxhall Pleasure Gardens.

IBIM integrates Building Information Modelling [BIM] and gaming into architectural visualisation. ${ }^{\mathrm{x}}$ IBIM uses BIM models to generate the game environment. Virtual building users or characters and other game components such as graphics (e.g. shaders and camera views), audio, physics, and artificial intelligence can be integrated into the games. The games can produce simulations of physical building dynamics and behaviours of virtual building users (see Figure 9 ).

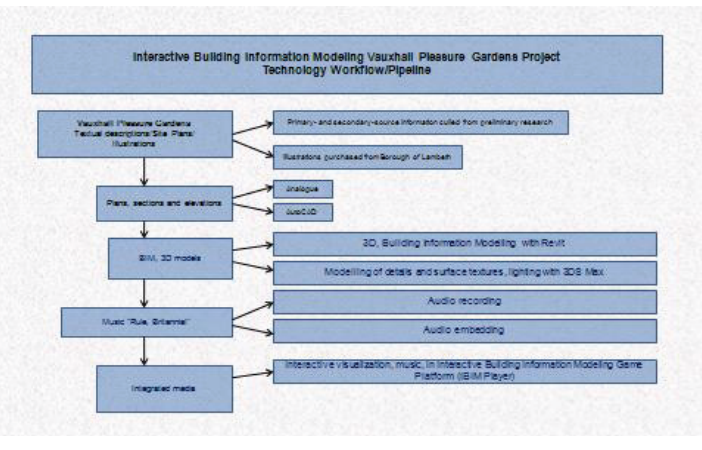

Figure 9: Project workflow

IBIM consists of the following three modules.

\section{BIM Module}

The BIM method models both geometric and nongeometric information of buildings. Such information may include the size, type, material, and location of building elements, and may also contain information that is important for historical building preservation. IBIM uses Autodesk ${ }^{\circledR}$ Revit $^{\circledR}$ Architecture as the tool for constructing the BIM module.

\section{Crossover module}

The Crossover module translates both geometric data and non-geometric data from BIM to a game through Revit's Application Programming Interface (API). The Crossover approach also enables texture baking that makes high-quality appearances and effects in real-time environments feasible by processing computationally complex simulations offline, such as global illumination, and rendering the solutions into texture maps, which games can process rapidly.

\section{Game module}

The system design uses the Microsoft $^{\circledR} \mathrm{XNA}^{\mathrm{TM}}$ Framework as the game platform. In the game module, animation allows the simulation of time passage in the model. Materials and lighting information also play an important role in games because they can make the geometry appear believable, giving visitors the feeling of immersion in a virtual world. Collision detection, gravity, and other physics simulations allow for real-time interactivity in games. The Game module also enables audio to be played during the game.IBIM utilises Microsoft ${ }^{\circledR}$ Xbox $360^{\mathrm{TM}}$ game controller whose buttons, triggers, and thumb sticks control the game, and this makes the navigation in building models more intuitive.

IBIM facilitates real-time interaction between visitors and the historic building model. It enables navigation options with first and third-person panoramic views, realistic graphics and sound effects. 
The audio for this research project will be integrated into the IBIM-Game software using the Microsoft $^{\circledR} \mathrm{XNA}^{\mathrm{TM}}$ game Applications Programming Interface. Audio will be created in the form of a wave file that can be imported into the XNA Game Studio Integrated Developer Environment (IDE). The wave file will be converted into an XNA content file automatically at compile time using the IDE.XNA SoundEffect and SoundEffectInstance classes will be used to play the audio when the user navigates the building. The audio content file will be loaded into an instance of SoundEffect when the BIM-Game starts. Audio controls for starting, pausing, stopping, looping, and volume adjustment will be handled using the functionality of the SoundEffectlnstance class. As development progresses, additional sound files will be added to the game so that visitors can select the composition that plays while s/he explores the structures and spaces of the gardens.

\section{DELIVERY}

Currently, anyone with an .edu email address can request to download and use IBIM for free for educational purposes. We have also provided evaluation licenses for non .edu email addresses. Requests for the software can be made through the SELab web site.Alternatively, the Vauxhall model could be packaged in a single zip file that could be distributed in a number of different ways, including DVD, web site and file transfer protocol [FTP], among others.

Delivery methods currently under consideration include allowing users to download the Vauxhall model and IBIM together. They can then follow similar steps to download and install them as they do now for IBIM (with a house sample). In this scenario, they would then run IBIM within Revit and load the Vauxhall model for play. This is the current method of running the game.

There may be improved and simplified delivery methods specific to this project. For example, we can create a standalone game without the requirement of Revit. Additionally, we are exploring the possibility of making the game into anXBox 360 game so a game DVD can be used to deliver the game and users will play it on an XBox 360 console.

\section{CONCLUSIONS}

As a process and as a product of digital technological development, the Vauxhall IBIM project promises to improve our understanding of affective experience in the visual and spatial realms of 18th-century London. Whether using the Vauxhall IBIM game for entertainment or for research, students and scholars of visual and spatial literacies will have the opportunity to engage cultures of display within the framework of a digitally-generated period Sensorium. Those visitors whose reception has been conditioned by modern and post-modern exhibition practices will gain greater appreciation for alternative schemes of exhibition and reception, which will in turn inform and perhaps even help to reform those practices in the 21st century. As the project moves forward through the processes of informal open source development and formal collaborative modification, Vauxhall IBIM will broaden to include the entire pleasure gardens site while at the same time increasing in specificity of detail as minute elements are added through texture mapping. However, it is important at this early stage to remain mindfulof various factors relevant to the historical realities and philosophical impulses that inform this project. The IBIM Vauxhall Music Hall rotunda and annex here introduced will foreverrepresent anaccretion of individual choices rather than an exact replica of an architecturally authentic monument pinpointed to a moment of historical specificity. Second, regardless of advancements in rendering, animation and sound delivery software capabilities, the driver of this project is and shall remain the affective, multisensory experience of the structures, spaces and stimuli of Vauxhall Pleasure Gardens. Toward that end we will continue to focus on the various visual and non-visual stimuli that contributed to those formations.

\section{ACKNOWLEDGMENTS}

The authors would like to acknowledge Jacob Morris, whose archival research uncovered a wealth of information relevant to the structural, spatial and imagined elements of Vauxhall Pleasure Gardens. Professor AnatGeva's generous consultations with our research technicians provided invaluable guidance on the history of building technology and materials. Professor Mark Clayton, who patiently tutored the art historian in the basics of Revit software, called the author's attention to the potential of IBIM for use in digital heritage projects. Mallory Schramm provided administrative and communications support that allowed the project to proceed.

\section{REFERENCES}

Cameron, F. and Kenderdine, S. eds (2007) Theorizing digital cultural heritage: a critical discourse.Cambridge, MIT Press.

Di Bello, P. and Koureas, G. eds (2010) Art, history and the senses: 1830 to the present. Ashgate, Aldershot. 
Flynn, B. Digital Knowledge as Archaeological Spatial Praxis. InProc of the 13th Intl Conference on Virtual Systems and Multimedia, Brisbane, 2326 September 2007, pp. 85-91.

Frischer, B. (2008) From digital illustration to digital heuristics.In Frischer, B. and Dakouri-Hild, A., (eds), Beyond Illustration: $2 d$ and 3d Digital Technologies as Tools for Discovery in Archaeology.Archaeopress, Oxford.

Nosan, G. (2002) Pavilions, power, and patriotism:garden architecture at Vauxhall. In Conan, M. (ed) Bourgeois and Aristocratic Cultural Encounters in Garden Art, 1550-1850. Dumbarton Oaks, Washington DC.

Texas A\&M University Sustainability and Energy Laboratory URL: http://SELab.arch.tamu.edu/

' See David Coke's website for bibliographic information:http://www.vauxhallgardens.com

iiBernard Frischer, 'From digital illustration to digital heuristics', in Frischer, B. and Dakouri-Hild, A. (eds), Beyond Illustration: $2 d$ and $3 d$ Digital Technologies as Tools for Discovery in Archaeology (Oxford, Archaeopress, 2008) p. v.

iii Bernadette Flynn, 'Digital Knowledge as Archaeological Spatial Praxis',Proceedings of the 13th Intl Conference on Virtual Systems and Multimedia, Brisbane, 23-26 September 2007, pp. 85-91.

${ }^{\text {iv }}$ Sarah Kenderdine, 'Speaking in Rama:Panoramic Vision in Cultural Heritage Visualization', in Cameron, F. and Kenderdine, S. (eds), Theorizing digital cultural heritage: a critical discourse(Cambridge, MIT Press, 2007) pp. 301332, p. 301.

'Michael Baxandall coined the term 'period eye' in Painting \&Experience in Fifteenth-Century Italy (Oxford, Oxford University Press, 1972).For 'period Sensorium' see Patrizia di Bello and Gabriel Koureas (eds), Art, History and the Senses: 1830 to the Present (Aldershot, Ashgate, 2010).

viUNESCO World Heritage 1001 wonders site URL: http://www.world-heritage-tour.org/

vii See Kimberley Rorshach, 'Frederick, Prince of Wales (1707-1751) as collector and patron,' Walpole Society 55 (1989-1990) pp. 1-76.

viiiGregory Nosan, 'Pavilions, Power, and Patriotism:Garden Architecture at Vauxhall', in
Conan, M. (ed) Bourgeois and Aristocratic Cultural Encounters in Garden Art, 1550-1850 (Washington DC, Dumbarton Oaks, 2002) p. 120.

ix John Entick, A New and accurate survey of London, Westminster, Southwark, and places adjacent (London, printed for Edward and Charles Dilly, 1766) vol. IV, p. 448.

$x$ 'A New Song', printed inA hint to the fair sex.A garland containing six new songs (c. 1762).

xi IBIM, 2010. URL: http://SELab.arch.tamu.edu/ Last accessed: 4/2/2010.Yan, W., Culp, C., and Graf, R. (2010) Gaming and BIM Impact on Architectural Visualization. Submitted to Automation in Construction, Elsevier. Under review. 